\title{
Durability vs technical - the usage properties of road pavements
}

\author{
Izabela Skrzypczak ${ }^{1,}{ }^{*}$, Wojciech Radwański ${ }^{2}$, and Tomasz Pytlowany ${ }^{2}$ \\ ${ }^{1}$ Rzeszow University of Technology, Aleja Powstancow Warszawy 12, Rzeszów, Poland \\ ${ }^{2}$ PWSZ Krosno, ul. Rynek 1, Krosno, Poland
}

\begin{abstract}
Contemporary trends in development and new material and technical solutions for road pavement should consider the permanent increase in the growth of traffic as well as aspects of environmental protection and balanced development. Nowadays, attempts are made towards estimation of the appropriate thickness for pavement construction already in the phase of its design. Flexible pavements are preferred over rigid concrete roads because of their certain advantages, such as they can be strengthened and improved in stages with the growth of traffic. Flexible pavements are less expensive in regards to their initial cost and maintenance. Concrete pavements are nowadays becoming more popular. The largest advantage for using rigid pavement is its durability and ability to hold its shape against traffic and difficult environmental conditions. Although concrete pavement is less expensive, it requires less maintenance and has a good design life. The main objective of this study is to present a comparative review on the suitability of pavement depending on various parameters such as material, loading, longer life, cost effectiveness etc.
\end{abstract}

\section{Definition of durability}

According to the PN-EN 1990 Basis for Construction Design [1], constructions should be designed in such a way that changes occurring in a projected exploitation time, considering the environmental influence and estimated maintenance level do not lower construction usage properties below an intended level. Environmental conditions should already be determined in the stage of design so that it is possible to assess their meaning in the context of durability, and undertake the appropriate means to protect materials used in construction.

To ensure correct structure durability it is recommended to consider:

- intended or estimated usage of structure;

- expected environmental conditions;

- composition and behaviour of materials and products

- properties of the ground

- type of construction of the structure

- quality of realization and level of control

- special protective means

- intended maintenance in the projected time of use.

* Corresponding author: izas@prz.edu.pl 
Degradation may be assessed based on calculations and experimental tests experience gained from earlier realizations or a combination of all these approaches.

A highway pavement is a structure consisting of superimposed layers of processed materials above the natural soil subgrade, whose primary function is to distribute the applied vehicle loads to the subgrade [3]. The pavement structure should be able to provide a surface of acceptable riding quality, adequate skid resistance, favourable light reflecting characteristics, and low noise pollution. The ultimate aim is to ensure that the transmitted stresses due to wheel load are sufficiently reduced, so that they will not exceed the bearing capacity of the subgrade.

A highway pavement, because of its exploitation conditions, damaging factors and the technologies used in road building are the most difficult engineering constructions, both in analyses and design, even though they belong to the most simple ones for realization.

Flexible pavements are most commonly used. For flexible pavements, it is very important to properly characterize the behaviour of subgrade soils and unbound aggregate layers as the foundations of the layered pavement structure [4]. Flexible pavements will transmit wheel load stresses to the lower layers through grain-to-grain transfer through the points of contact in the granular structure. The wheel load acting on the pavement will be distributed to a wider area, and the stress decreases with the depth. Taking advantage of this stress distribution characteristic of flexible pavements normally has many layers. Hence, the design of flexible pavement uses the concept of a layered system [3]. Flexible pavements generally suffer from rutting which results from heavy traffic and severe environmental condition [5]. Flexible pavements are those having negligible flexural strength and are flexible in structural actions under loads. [14]

The major flexible pavement failures are fatigue cracking, rutting, and thermal cracking. The fatigue cracking of flexible pavement is due to the horizontal tensile strain at the bottom of the asphaltic concrete. The failure criterion relates the allowable number of load repetitions to tensile strain and this relation can be determined in a laboratory fatigue test on asphaltic concrete specimens. Rutting occurs only on flexible pavements as indicated by a permanent deformation or rut depth along the wheel load path. Rutting in flexible pavements is a major distress mode and relatively difficult to simulate in computational analyses, mainly for the following reasons:

- the constitutive relations of the materials are nonlinear and complex. Most pavement materials are very difficult to characterize under repeated and moving loads.

- the asphalt concrete material is viscoelastic and viscoplastic, i.e., strong loading time and temperature dependent. The other unbound materials base, sub base, and subgrade are only slightly time depenent.

- the temperature and moisture of the materials vary with every load repetition.

Rigid pavements have sufficient flexural strength to transmit the wheel load stresses to a wider area below. Compared to flexible pavement, rigid pavements are placed either directly on the prepared subgrade or on a single layer of granular or stabilized material. Since there is only one layer of material between the concrete and the subgrade, this layer can be called base or sub-base course [3]. In rigid pavement, the load is distributed by the slab action, and the pavement behaves like an elastic plate resting on a viscous medium. Rigid pavements are constructed with Portland cement concrete (PCC) and should be analysed using the plate theory instead of layer theory, assuming an elastic plate resting on a viscous foundation. The plate theory is a simplified version of the layer theory that assumes the concrete slab as a medium thick plate, which is plane before loading and is to remain plane after loading. The bending of the slab due to wheel load and temperature variation results in tensile and flexural stress. The stress condition of rigid pavement was analysed using finite element analysis [12]. The cement concrete pavement slab can very well serve as a wearing surface as well as an effective base course. Therefore, usually the 
rigid pavement structure consists of a cement concrete slab, below which a granular base or sub base course may be provided [14]. Concrete pavements, often called rigid pavements, are made up of Portland cement concrete and may or may not have a base course between the pavement and subgrade. As a general rule, the concrete, exclusive of the base, is referred to as the pavement. The concrete pavement, because of its rigidity and high modulus of elasticity, tends to distribute the applied load over a relatively wide area of soil; thus, the major portion of the structural capacity is supplied by the slab itself [18].

\section{Durability and conditions of use of road pavements}

Road pavements undergo surface and structural damage under the influence of traffic load and climatic conditions. Damages correspond to the type of pavement and materials used for it's construction, thus flexible pavement may undergo the following damages: deformation in the subgrade is transferred to the upper layers, design is based on load distributing characteristics of the component layers, flexible pavement carries low flexural strength, load is transferred by grain to grain contact, have low completion cost but repair cost is high, have a low life span (High Maintenance Cost), surfacing cannot be laid directly on the subgrade but a sub-base is needed, no thermal stresses are induced as the pavement has the ability to contract and expand freely, expansion joints are not needed, the strength of the road is highly dependent on the strength of the subgrade, rolling of the surfacing is needed, road can be used for traffic within 24 hours, the force of friction is less, and deformation in the subgrade is not transferred to the upper layers, damaged by oils and certain chemicals

On the other hand, rigid pavement undergoes the following damages: deformation in the subgrade is not transferred to subsequent layers, design is based on flexural strength or slab action, rigid pavement carries high flexural strength, no such phenomenon of grain to grain load transfer exists, have low repairing cost but completion cost is high, life span is more as compare to flexible (Low Maintenance Cost), surfacing can be directly laid on the subgrade, thermal stresses are more vulnerable to be induced as the ability to contract and expand is much less in concrete, expansion joints are needed, the strength of the road is less dependent on the strength of the subgrade, rolling of the surfacing in not needed, road cannot be used until 14 days of curing have passed, the force of friction is high, and no damage by oils and greases.

The designing of new road pavements and the strengthening the ones already existing in Poland has got a special meaning, especially recently when our road networks were included in the trans-European system. In this situation it became necessary to adjust the basic road network to load standards in the European Union in trans-border traffic where the load allowed for a vehicle axle is 11,5 tons (until now the axial load allowed in Poland was 10,0 tons). This change of the axial load causes the change of its influence on pavement structure mainly due to the fatigue of structure construction. A greater load causes higher stress and strain deformation at the bottom of the structure, for both the asphalt one and the concrete one. An increase in vehicle axial load is even more harmful for the concrete structure [1]. An increase of the load becomes a reason for pavement damage $[2,3,5,6]$. The costs of additional damages are considerable and are increasing along with lowering the road quality:

- a vehicle with a single axial load of 11,5 tons on a road where the allowable load is 10,0 tons / axle, will cause a damage amounting to $1,33 \mathrm{zl} / \mathrm{km}$,

- the same vehicle, with a single axial load of 11,5 tons, on a provincial road where the allowed load is $8,0 \mathrm{kN} /$ axle will cause damage amounting to $12 \mathrm{zl} / \mathrm{km}$,

- however, a vehicle with a single axial load of $11,5 \mathrm{t}$ on district or community roads will cause a damage of $40 \mathrm{zl} / \mathrm{km}$. 
Next to being influenced by traffic, the road pavement is also influenced by environmental factors that include water, glazed frost, acid rains and temperature. Temperature amplitude in the exploitation of pavement is extremely important, especially for asphalt structures made of mineral - asphalt mixtures which are thermoplastic materials and change properties depending on the temperature. In higher temperatures they may have permanent deformations and in low temperature they can crack. That is why the appropriate choice of material is so important. In Poland, in continental climate conditions, the environmental requirements are very difficult to achieve due to the high air temperature amplitudes from $+30 \mathrm{C}$ in the summer to $-20 \mathrm{C}$ in the winter. Thus, pavement temperatures may be from $+60 \mathrm{C}$ to $-30 \mathrm{C}$. Such a broad range of temperatures requires special care while choosing materials, especially asphalt binders. Requirements for road pavements consider both technical - usage and environmental aspects. Technical-usage aspects include:

- mechanical features:

resistance to deformation,

resistance to cracking,

load carrying capacity.

- comfort and user safety:

evenness,

roughness.

Environmental requirements concern the whole life cycle of the pavement:

- from the stage of construction; pavements should be made in a way and of materials which do not threaten the environment,

- phases of exploitation of the structure should contribute to lowering the arduousness of truck transportation for the road users and for the surrounding environment,

- after exploitation: materials used in road building should be recycled and, when used again they cannot change into scrap arduous to the environment.

The necessity of meeting all these diversified, sometimes even opposing requirements (resistance to deformation and resistance to low temperature cracking) resulted in the generalization of the notion of the functional division of pavement layers and a belief in the necessity of using different binders and mixtures for individual pavement layers.

\section{Durability and rehabilitation of road pavements}

The durability of pavements should be understood as a set of features decisive for the time of road exploitation and the costs of its maintenance [2-15]. They include:

- resistance to traffic load:

- fatigue durability,

- resistance to deformation (lateral and longitudinal evenness),

- resistance to environmental factors:

- resistance to cracking (low temperature - thermal fatigue),

- resistance to water and anti-freezing agents.

Control over fatigue durability is exercised by the construction of road pavement, the thickness and the quality of layers, i.e. the mechanical properties of materials.

The strategy for maintaining the correct structure conditions for a given type of pavement construction must consider maintenance treatments carried out with the right frequency so that they prevent excessive pavement damage which may be responsible for lowering its structural durability. However it must be remembered that pavements which do not require maintenance treatments do not exist (Fig. 1). 


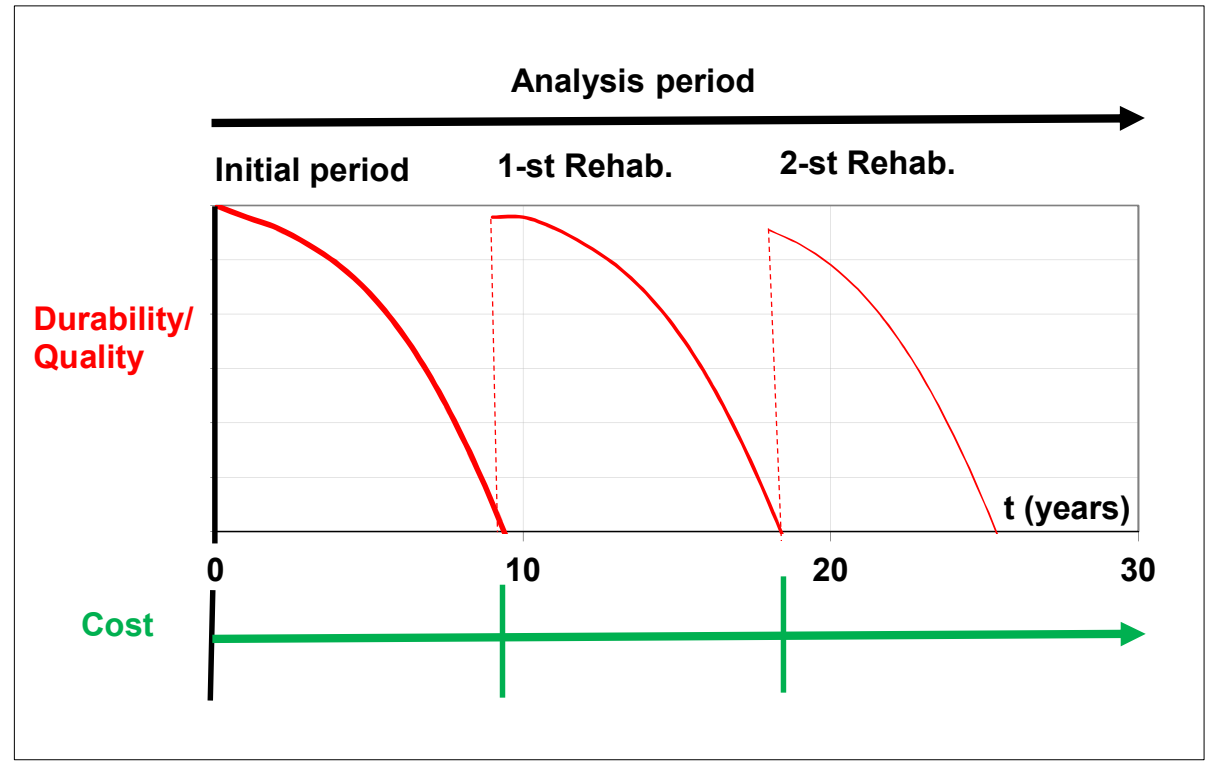

Fig. 1. The schematic of durability/quality and cost on the life of the asphalt pavements.

The designed exploitation durability of concrete structures is 30 years with practically zero maintenance costs. For such a time of exploitation, the estimated maintenance costs for concrete structures include an exchange of dilatation and an exchange of $15 \%$ of concrete layer surface. The designed exploitation time for asphalt structures is 25 years. In this time it is necessary to consider a triple exchange of wear off layers, i.e. the costs of the exchange to be borne every 9 years. The intensity of damage increases over time, especially in long term exploitation.

The time from the execution until the moment when usage properties obtain the lowest acceptable level is determined as usage/exploitation time, it can be obtained through different means; by designing and execution of a very durable structure or by using an appropriate repair and maintenance treatment when exploitated.

\section{Cost analysis}

After a cost determination of the initial pavement, maintenance, rehabilitation, salvage value and users cost for one kilometre, the present worth of rigid and flexible pavements is calculated.

The Present Worth formula used, is shown below (1):

$$
P W=I c+\sum_{1}^{t} M c+\sum_{1}^{t} R c+\sum_{1}^{t} U c
$$

and: Ic - initial construction cost, Mc - maintance, Rc - Rehabilitation cost, Uc - user cost (user time and fuel saving cost), $\mathrm{N}$ - numebr of years (30 years).

The Life Cycle Cost Analysis period should have to be sufficiently long enough to reflect the long-term cost differences associated with reasonable design strategies. The analysis period should always be longer than the pavement design period, except in the case of extremely long-lived pavements. As a rule of thumb, the analysis period should be long enough to incorporate at least one rehabilitation activity. The FHWA's 1996 Final LCCA Policy statement recommends an analysis period of at least 35 years for all pavement 
projects, including new or total reconstruction pojects as well as rehabilitation, restoration, and resurfacing projects [12].

As per the above recommendation period of 30 years, including one rehabilitation time for the rigid pavement was considered for the analysis. The design period of 30 years for the respective pavements were taken from the design documents.

The calculated Net Present Worth for $1 \mathrm{~km}$ for rigid and flexible pavement is presented in Table 1.

Table 1. Present Worth (PW) of a 2 x 3,5m length of road $1000 \mathrm{mb}$ and for traffic category KR2 for the analyzed pavements.

\begin{tabular}{|c|c|c|}
\hline Cost in zl in 1 kilometer & Rogid Pavement & Flexible Pavement \\
\hline Initial Construction Cost & 1337893.47 & 1441841.88 \\
\hline Routine Maintance Cost & 187468,78 & 1933328,25 \\
\hline Periodic Maintance Cost & 194192,50 & 990780,00 \\
\hline Rehabilitation Cost & 2433402,8 & 1716782,55 \\
\hline Total maintance & 2815064.08 & 4640890.80 \\
\hline Total Cost in 30 years & 4152957,55 & 6082732,68 \\
\hline
\end{tabular}

The initial cost is generally the major factor in deciding the type of pavement in the design. The planners often think that the flexible pavement is cheaper than the rigid pavements. In fact, this is not always the case. Many researchers perform a cost analysis of pavements. The initial cost of rigid pavement is high but by considering serviceability and the life of rigid pavement it is found that it is more economical than the flexible pavement. The construction costs for rigid pavements are cheaper than flexible pavements, in contrast to what is generally thought. However with the strength increase in subgrade, the asphalt pavement costs and rigid pavement costs get closer. With increasing petrol prices the cost of asphalt pavements will be even higher. So, concrete pavement should be highly considered in choosing the pavement types [16].

Rigid pavement carries higher flexural strength than flexible pavement, i.e. it handles bending and deformation without rupturing under wheel axial load. In flexible pavement, the load is transferred from grain to grain and because of that many failures occurs such as fatigue cracking, rutting and thermal cracking. Yet, in rigid pavement no such phenomenon of grain to grain load transfer exists, hence there are fewer amounts of failure. The life span of rigid pavement is longer than the flexible pavement with low maintenance costs. The life-cycle cost of flexible pavement will be about $32 \%$ higher than the rigid pavement after 30 years. The initial cost of rigid pavement is higher but when comparing the total cost of pavement through its life span, the rigid pavement is more economical than the flexible pavement. The initial cost of rigid pavement (concrete pavement) is reduced by replacing cement with fly ash at some percent or by using other alternatives.

\section{Summary}

Based on the results of the research study, it was found that the rigid pavement has a longer service life (more than double) than the flexible pavemnt. For $1000 \mathrm{mb}$ road length, the life- 
cycle cost of the rigid pavement is lower by a $32 \%$ than the flexible pavement in a 30 -year anaysis period. The routine and periodic maintaince cost for the this exploitation time are 2,3 times greater than the initial construction cost of the same one kilometer stretch for flexible pavement. For flexible pavement, the total cost is higher for maintenance and rehabilitation as compared to rigid pavement. Also, it has also been presented that the rigid pavement has a lower maintaince and rehabilitation cost when compared to the flexible pavement. On the other hand, the rigid pavement, which is wholly constructed with local materials, such as cement and aggregates without the requirement of importing construction materials from abroad. In the history of road construction in Poland, concrete (rigid) pavement comaprised only about $10 \%$ of the total road network due to the lack of construction technology and practice in spite of its advvantage. Contemporary trends in development and new material - technological solutions for road pavements should consider the permanent growth of traffic load as well as the aspect of environmental protection and balanced development. Nowadays, in the phase of structural design, attempts are made to assess the appropriate values of thickness of a pavement structure. Construction layers are determined on the basis of traffic category in a projected exploitation time and the repeatability of a load that is to be carried/withstood by the structure before its breakdown for a given type of failure / damage. The breakdown of asphalt pavements is the result of fatigue.

But forecasting failure / damage is burdened with a high level of uncertainty because of considerable natural changeability connected with thegreat number of incoming parameters, thus the analyses of the durability of structures require a probabilistic approach based on the analyses of reliability which enable the use of all incoming parameters decisive for the durability of a road structure over time. In the case of road parameters, it is necessary to distinguish between the durability of the wear off layer from the durability of the pavement structure. On the other hand, the durability of pavement structure depends on the structure condition ( structural damage) which results from traffic use on the road. Traffic causes periodical stress and strain deformations in the structure, which in long term exploitation is the reason for fatigue cracks. This is why the analyses related to materials research are so important [17-21]. The presented analyses of the reliability for asphalt and concrete structures are capable of meeting both the economic and durability requirements as well as the balanced development and environmental requirements.

\section{References}

1. PN-EN 1990:2004 Basic design rules of structures

2. J. Deja, Polish roads, Review of Road and Bridge Technique (in Polish) (2003)

3. Tom V. Mathew and K V Krishna Rao, - Introduction to Transportation Engineering\|, NPTEL May 3, (2007)

4. Minkwan Kim, A.M.ASCE, ErolTutumluer, M.ASCE and Jayhyun Kwon, -Nonlinear Pavement Foundation Modeling for Three-Dimensional Finite-Element Analysis of Flexible Pavements\|, International Journal of Geomechanics, ASCE/ (2009)

5. T. Arvo, Introduction to Concrete Pavementsl, Introduction to Concrete Pavements, EestiBetooniühing, (2013).

6. J. Deja, P. Kijowski, II,https://edroga.pl/drogi-i-mosty/drogi-betonowe-doswiadczeniaz-budowy-i-eksploatacji-cz-ii-22062301/all-pages

7. M. Gruszczyński, Przegląd Budowlany, 1 (2016)

8. P. Woyciechowski, K. Harat, Construction Technology Architecture, (2012) 
9. M. Senderski, Construction Engineer, 4 (2015)

10. Frost Durability of Roller Compacted Pavements, Canada, Portland Cement Association (2004)

11. Roller Compacted Concrete Pavements Design and Construction, US Army Corps of Engineers, Washington DC (2000)

12. T. Chou Yu, Comparative Analyses Of Rigid Pavementsl, Journal of Transportation Engineering, ASCE, 109(5), (1983)

13. Chou Yu T. Comparative Analysis of Rigid Pavement. ASCE-JTE.1983, 109 (05):669$688 \mathrm{p}$

14. A. Dewangan, Dr. D.P.Gupta, Dr. R.K.Bakshi, International Journal of Computer Technology and Electronics Engineering (IJCTEE), Vol 2, ISSN 2249-6343

15. General Technical Specifications, Roller Compacted Concrete of Pavements, GDDKiA, Warszawa (2013)

16. Sz. Woliński, K. Wrobel, Reliability of building structures, OPRz, Rzeszow (2001)

17. L. Czarnecki, P. Woyciechowski, G. Adamczewski, KSCE Journal of Civil Engineering, 22(2), pp 755-764 (2018)

18. https://www.researchgate.net/publication/306914416_A_Comparative_Study_on_Rigi d_and_Flexible_Pavement_A_Review (accessed May $2 \overline{5}$ 2018)

19. L. Czarnecki, P. Woyciechowski, ACI Materials Journal, 109(3), pp 275-282 (2012)

20. M. Dobiszewska, Journal of Materials Education, 39(5-6), pp 133-156 (2017)

21. A. Beycioglu, A. Gultekin, H. Aruntas, Y. Huseyin et al., 20(2), pp 247-255 (2017)

22. J. Konkol, G. Prokopski, IMAGE Analysis \& Stereology, 30(2), 89-100 (2011)

23. A. Szydło, Ed. Polish Cement (2004)

24. A. Szydło, P. Mackiewicz, Ed. Polish Cement (2005)

25. J. Deja, Roads: Land Roads, Air roads, Water roads (2009)

26. Production of Roller Compacted Concrete, Portland Cement Association (2008)

27. R. Miller, Compaction of Roller-Compacted Concrete (2000)

28. Guide Specification for Construction of Roller-Compacted Concrete Pavements, American Concrete Institute, Farmington Hills (2004).

29. Optimum Flexible Pavement Life-Cycle Analysis Model. Available from: https://www.researchgate.net/publication/245306205_Optimum_Flexible_Pavement_L ife-Cycle_Analysis_Model (accessed May 25 2018)

30. http://www.fdot.gov/design/training/designexpo/2012/Presentations/UwaibiEmmanuelPavementTypeSelectionProcess\%20.pdf(accessed May 25 2018) 